\title{
Kompatibilitas dan Daya Hambat Konsorsium Trichoderma spp. Endofit terhadap Penyakit Busuk Buah Kakao Phytophthora palmivora
}

\author{
Fifi Puspita*, Muhammad Ali, dan Supriyadi \\ Fakultas Pertanian, Universitas Riau \\ Jalan H.R. Soebrantas Km. 12,5 Simpang Baru , Pekanbaru 28293 \\ *Alamat korespondensi: fipspt@gmail.com
}

\begin{abstract}
Compatibility and inhibition activity of endophytic Trichoderma spp. consortium against cacao pod rot disease Phytophthora palmivora
\end{abstract}

\begin{abstract}
Phytophthora palmivora can cause cocoa pod rot that causes economic losses. Control that can be used is the use of Trichoderma biological agents. The use of Trichoderma in control can be carried out singly or in a consortium with various types of Trichoderma or other microbes. The research aimed to observe the compatibility of some endophytic Trichoderma spp. and obtain the consortium with the highest inhibition on P. palmivora growth in vitro and on cocoa black pod disease. This research was conducted at the Plant Laboratory of the Faculty of Agriculture, Universitas Riau from August to October 2018. This research using four treatments of $\mathrm{T} 1=$ Trichoderma spp. endophytic from oil palm root (TR), T2= Trichoderma spp. endophytic from oil palm stem (TS), T3= Trichoderma spp. endophytic from oil palm fronds (TP), T4= TR + TS, T5 = TR + TP, T6= TS + TR, T7 = TR + TS + TP, study consisted of 3 steps : 1) compatibility test of endohytic Trichoderma spp., 2) in-vitro inhibition test to P. palmivora and 3) application of endophytic Trichoderma spp. to control P. palmivora. Results of the research showed that Trichoderma TR-01, TS-02 and TM-01 isolates were compatible. The combination of TR-01+TS02+TM-01 provided the highest inhibition to P. Palmivora growth in-vitro (72.97\%). The consortium also showed the best ability to suppress the intensity of cocoa black pod diesease.
\end{abstract}

Keywords: Trichoderma spp. endophytic, compatibylity, combination, cocoa pod.

\begin{abstract}
ABSTRAK
Phytophthora palmivora dapat menyebabkan penyakit busuk buah kakao yang menimbulkan kerugian secara ekonomi. Pengendalian yang dapat digunakan adalah penggunaan agens hayati Trichoderma. Penggunaan Trichoderma dalam pengendalian dapat dilakukan secara tunggal maupun secara konsorsium dengan berbagai jenis Trichoderma maupun mikroba lainnya. Penelitian ini bertujuan untuk mengetahui kompatibilitas konsorsium Trichoderma spp. endofit dan memperoleh kombinasi isolat Trichoderma spp. endofit yang mempunyai daya hambat tertinggi terhadap pertumbuhan $P$. palmivora secara in-vitro dan terhadap penyakit busuk buah kakao. Penelitian ini dilaksanakan di Laboratorium Penyakit Tumbuhan Fakultas Pertanian Universitas Riau pada bulan Agustus hingga Oktober 2018. Penelitian dilaksanakan secara eksperimen dengan perlakuan $\mathrm{T}_{1}=$ Trichoderma spp. endofit asal akar kelapa sawit (TR), $\mathrm{T}_{2}=$ Trichoderma spp. endofit asal batang kelapa sawit (TS), $\mathrm{T}_{3}=$ Trichoderma spp. endofit asal pelepah kelapa sawit (TP), $\mathrm{T}_{4}=\mathrm{TR}+\mathrm{TS}, \mathrm{T}_{5}=\mathrm{TR}+\mathrm{TP}, \mathrm{T}_{6}=\mathrm{TS}+\mathrm{TR}, \mathrm{T}_{7}=$ TR + TS + TP, yang terdiri dari 3 tahap yaitu: 1) uji kompatibilitas jamur Trichoderma spp. endofit, 2) uji daya hambat konsorsium Trichoderma spp. endofit dan 3) uji kemampuan konsorsium Trichoderma spp. endofit untuk mengendalikan penyakit busuk pada buah kakao. Hasil penelitian menunjukkan bahwa Trichoderma endofit isolat TR-01, TS-02 dan TM-01 bersifat kompatibel sehingga dapat digabungkan. Kombinasi (TR-01+TS-02+TM-01) memiliki daya hambat yang tertinggi terhadap pertumbuhan $P$. palmivora secara in-vitro yaitu $72,97 \%$. Kombinasi isolat Trichoderma tersebut juga memiliki kemampuan terbaik untuk mengendalikan penyakit busuk pada buah kakao.
\end{abstract}

Kata kunci: Trichoderma spp. endofit, Kompatibel, Kombinasi, Busuk buah. 


\section{PENDAHULUAN}

Tanaman kakao (Theobroma cacao L.) merupakan salah satu tanaman perkebunan yang banyak dibudidayakan di Indonesia. Berdasarkan data dari Direktorat Jendral Perkebunan (2019) pada tahun 2017 produktivitas kakao di Indonesia mencapai $737 \mathrm{~kg} / \mathrm{ha}$, pada tahun 2018 mengalami penurunan produktivitas yaitu menjadi $729 \mathrm{~kg} / \mathrm{ha}$. Rendahnya produksi kakao di Indonesia dapat disebabkan oleh luas lahan penanaman yang masih kecil, kurang baiknya pemeliharaan dan adanya serangan hama serta patogen. Salah satu patogen yang dapat menginfeksi kakao adalah Phytophthora palmivora.

$P$. palmivora dapat menimbulkan kerugian pada areal perkebunan kakao, karena infeksi patogen ini dapat menyebabkan penyakit busuk buah, kanker batang dan hawar daun pada tanaman kakao. Berdasarkan hasil penelitian Fauzan dkk. (2013), intensitas penyakit busuk buah kakao yang disebabkan $P$. palmivora di Desa Sambirejo Kecamatan Binjai, Kabupaten Langkat mencapai 73,40\% dan Desa Karang Anyar Kecamatan Secanggang, Kabupaten Langkat mencapai 12,80\%. Data tentang penyakit busuk buah pada tanaman kakao di Provinsi Riau belum ada dilaporkan, namun berdasarkan pengamatan di lapangan penyakit tersebut relatif banyak ditemukan. Pengendalian penyakit karena $P$. palmivora yang umum dilakukan adalah dengan penggunaan fungisida sintetis, sanitasi lingkungan dan pengendalian secara mekanis. Namun demikian, pengendalian ini masih kurang efektif karena $P$. palmivora merupakan patogen tular tanah yang sebagian besar siklus hidupnya berada di dalam tanah yang dapat membentuk klamidospora. Alternatif lain yang dapat mengatasi masalah tersebut adalah penggunaan agens pengendali hayati. Salah satu agens hayati yang dapat digunakan adalah Trichoderma sp.

Penggunaan Trichoderma dalam pengendalian patogen dapat dilakukan secara tunggal maupun secara konsorsium dengan berbagai jenis Trichoderma maupun mikroba lainnya. Hasil penelitian Suwandi (2008) menunjukkan bahwa penggunaan konsorsium $T$. virens dengan isolat yang berbeda (T1+T4+T9+T11) memiliki kemampuan untuk menekan keparahan penyakit Rigidoporus lignosus dengan rata-rata 65\% serta dalam menekan sumber inokulum (miselium) dalam potongan kayu memiliki penekanan relatif sebesar 91\%. Puspita \& Nugroho (2015) menemukan beberapa isolat jamur genus Trichoderma yang merupakan jamur endofit dari jaringan kelapa sawit yaitu isolat TR01 (Trichoderma virens), TR02 (Trichoderma sp.), TR03 (Trichoderma sp.), TS02 (T. virens), TS03 (Trichoderma sp.) dan TM01 (T. virens) dan TM03 (Trichoderma sp.). Isolat-isolat $T$. virens endofit yang didapatkan belum pernah diuji kompatibilitas dan digunakan secara konsorsium untuk menghambat $P$. palmivora penyebab penyakit busuk buah kakao. Penelitian ini bertujuan untuk menguji kompatibilitas konsorsium Trichoderma spp. endofit dan memperoleh konsorsium isolat Trichoderma spp. endofit yang paling kompatibel serta yang mempunyai daya hambat tertinggi dalam mengendalikan Phytophthora palmivora penyebab busuk buah kakao secara in-vitro dan pada buah kakao.

\section{BAHAN DAN METODE}

Penelitian dilaksanakan di Unit Usaha Industri Biofertilizer Biopestisida Biological Control Community (BICCOM) dan Laboratorium Penyakit Tumbuhan Fakultas Pertanian Universitas Riau, Kampus Bina Widya km 12,5 Kelurahan Simpang Baru Kecamatan Tampan Pekanbaru. Penelitian dilakukan dari bulan Agustus 2018 sampai Oktober 2018. Penelitian dilaksanakan secara eksperimen dengan menggunakan Rancangan Acak Lengkap (RAL) yang terdiri dari 7 perlakuan dan 3 ulangan sehingga diperoleh 21 unit percobaan. Setiap unit percobaan terdiri dari 2 sub unit sehingga jumlah seluruhnya adalah 42 sub unit. Perlakuan yang diuji adalah :

$\mathrm{T}_{1}=T$. virens endofit asal akar kelapa sawit (TR-01)

$\mathrm{T}_{2}=T$. virens endofit asal batang kelapa sawit (TS-02)

$\mathrm{T}_{3}=T$. virens endofit asal pelepah kelapa sawit (TM-

01)

$\mathrm{T}_{4}=\mathrm{TR}-01+\mathrm{TS}-02$

$\mathrm{T}_{5}=\mathrm{TR}-01+\mathrm{TM}-01$

$\mathrm{T}_{6}=\mathrm{TS}-02+\mathrm{TM}-01$

$\mathrm{T}_{7}=\mathrm{TR}-01+\mathrm{TS}-02+\mathrm{TM}-01$

\section{Pembuatan suspensi dan konsorsium spora Trichoderma spp. endofit}

Pembuatan suspensi Trichoderma spp endofit dilakukan dengan menambahkan $10 \mathrm{ml}$ aquades steril pada medium PDA yang telah ditumbuhi koloni jamur Trichoderma spp. endofit berumur 7 hari setelah inkubasi, kemudian digosok dengan spatula agar konidia terlepas. Cairan dimasukan ke dalam tabung reaksi lalu diaduk 
dengan automatic mixer selama 5 menit agar menyebar merata dalam suspensi yang disebut larutan induk. Suspensi larutan induk kemudian diencerkan dengan cara mengambil $1 \mathrm{ml}$ untuk dicampur ke dalam $9 \mathrm{ml}$ aquades dan diaduk dengan automatic mixer selama 5 menit. Pengenceran dilakukan secara bertahap hingga diperoleh kerapatan spora Trichoderma spp endofit $\pm 10^{6}$ konidia/ml. Setelah suspensi Trichoderma spp. endofit jadi pembuatan suspensi dilakukan dengan mengkombinasikan suspensi Trichoderma spp. endofit sesuai perlakuan dengan perbandingan 1:1:1, sehingga diperoleh jumlah volume yang sama untuk setiap perlakuan.

\section{Pembuatan suspensi spora $P$. Palmivora}

Pembuatan suspensi $P$. palmivora dilakukan dengan menambahkan $10 \mathrm{ml}$ akuades steril pada medium PDA yang telah ditumbuhi koloni jamur $P$. palmivor berumur 7 hari setelah inkubasi, kemudian digosok dengan kuas halus agar konidia terlepas. Cairan dimasukan ke dalam tabung reaksi lalu diaduk dengan automatic mixer selama 5 menit agar menyebar merata dalam suspensi yang disebut larutan induk. Suspensi larutan induk kemudian diencerkan dengan cara mengambil $1 \mathrm{ml}$ untuk di campur kedalam $9 \mathrm{ml}$ aquades dan diaduk dengan automatic mixer selama 5 menit. Pengenceran dilakukan secara bertahap hingga diperoleh kerapatan spora $P$. palmivora $\pm 10^{6}$ konidia $/ \mathrm{ml}$. Perhitungan spora dilakukan dengan haemocytometer.

\section{Uji kompatibilitas Trichoderma spp. endofit}

Uji kompatibilitas dilakukan untuk mengetahui apakah antar isolat yang digunakan tidak saling menghambat. Ketiga isolat jamur diletakkan di atas permukaan medium PDA steril dalam satu cawan petri dengan jarak antar isolat $3 \mathrm{~cm}$. Pengamatan kompatibilitas dilakukan dengan melihat kompatibel atau tidak kompatibelnya masing-masing isolat yang ditunjukkan dengan ada tidaknya zona hambat.

Uji daya hambat konsorsium Trichoderma spp. endofit terhadap pertumbuhan $P$. palmivora secara in-vitro

Uji daya hambat konsorsium Trichoderma spp. endofit terhadap $P$. palmivora dilakukan dalam cawan Petri yang telah berisi Potato Dextrose Agar (PDA) steril. Dua kertas saring steril berbentuk bulatan dipotong dengan diameter $5 \mathrm{~mm}$. Satu kertas saring dicelupkan kedalam suspensi konsorsium $T$. virens dengan kerapatan konidia $10^{6} \mathrm{konidia} / \mathrm{ml}$ dan satu kertas saring lainnya dicelupkan ke dalam suspensi

$P$. palmivora dengan kerapatan konidia $10^{6}$ konidia/ml. Masing-masing potongan isolat diletakkan di bagian pinggir cawan Petri dengan jarak berlawanan $3 \mathrm{~cm}$. Perhitungan daya hambat dilakukan dengan rumus menurut Nugroho dkk. (2001) dalam Supriati dkk. (2010) sebagai berikut:

$$
P=\frac{\mathrm{d} 1-\mathrm{d} 1}{d 1} \times 100 \%
$$

Keterangan :

$\mathrm{P}=$ Persentase penghambatan

$\mathrm{d}_{1}=$ diameter koloni $P$. palmivora tanpa konsorsium

Trichoderma spp endofit.

$\mathrm{d} 2=$ diameter koloni $P$. palmivora dengan konsorsium Trichoderma spp endofit.

\section{Uji daya hambat konsorsium Isolat Trichoderma spp. endofit terhadap pertumbuhan} $P$. palmivora pada buah kakao

Suspensi spora konsorsium $T$. virens endofit sebanyak $200 \mathrm{ml}$ setiap perlakuan ditambah dengan Argistick sebanyak $2 \mathrm{ml}$ sebagai bahan perekat dan diaduk hingga tercampur merata. Suspensi konsorsium $T$. virens endofit selanjutnya disemprotkan ke buah kakao hingga merata dan dibiarkan selama 15 menit hingga suspensi pada permukaan buah tampak mengering. Inokulum $P$. palmivora dari biakan murni pada medium PDA diambil menggunakan cork borer berdiameter $5 \mathrm{~mm}$ dan ditempelkan pada bagian pangkal buah kakao yang telah dilukai dengan diameter luka $1 \mathrm{~cm}$. Buah yang telah diinokulasi $P$. palmivora kemudian disusun dalam kotak plastik yang telah diberi alas dengan 3 lembar kertas saring steril yang dilembabkan dengan aquades steril. Kotak kemudian ditutup dan disusun di dalam ruangan pada suhu kamar. Intensitas penyakit busuk buah kakao dihitung dengan rumus sebagai berikut:

$$
I=\frac{\sum_{i}^{n} n_{i} x v_{i}}{Z \times N} \times 100 \%
$$

\section{Keterangan :}

$\mathrm{I}=$ intensitas serangan

$\mathrm{n}_{\mathrm{i}}=$ Banyak buah yang diamati tiap katagori gejala (i $=0-4$ )

$\mathrm{Vi}=$ Nilai sekala kerusakan dari tiap katagori gejala $(\mathrm{i}$ $=0-4$ )

$\mathrm{Z}=$ Nilai sekala kerusakan tertinggi dari tiap katagori gejala

$\mathrm{N}$ = Banyak buah yang diamati 
Skala kerusakan dinilai berdasarkan kategori oleh Asaad dkk. (2010) sebagai berikut :

$0=$ tidak ada gejala serangan

$1=$ luas bercak coklat $0-25 \%$

$2=$ luas bercak coklat $>25-50 \%$

$3=$ luas bercak coklat $>50-75 \%$

$4=$ luas bercak coklat $>75-100 \%$

\section{Analisis data}

Data uji kompatibilitas dianalisis secara deskriptif dan ditampilkan dalam bentuk tabel dan gambar. Hasil uji daya hambat dianalisis secara statistik dengan sidik ragam dengan menggunakan program SAS 9.1.3. Hasil analisis ragam dilanjutkan dengan uji lanjut Beda Nyata Jujur (BNJ) pada taraf 5 $\%$, untuk membandingkan rata-rata antar perlakuan.

\section{HASIL DAN PEMBAHASAN}

Kompatibilitas antar isolat Trichoderma spp. endofit Hasil uji kompatibilitas tiga isolat Trichoderma spp. endofit asal tanaman kelapa sawit yaitu isolat TR-01 (asal akar), TS-02 (asal batang) dan TM-01 (asal pelepah) menunjukkan bahwa ketiga isolat Trichoderma spp. endofit yang diuji secara bersamaan pada medium PDA adalah kompatibel antara satu isolat dengan isolat lainnya (Tabel 1).
Isolat Trichoderma spp. endofit yang diuji dapat tumbuh secara bersamaan dan tidak saling menghambat antar isolat (Gambar 1). Kompatibilitas antar isolat jamur Trichoderma spp. endofit yang diuji dapat disebabkan ketiga isolat tersebut memiliki karakteristik antifungi yang sama, selain itu isolat ini diperoleh dari jenis tanaman yang sama yaitu tanaman kelapa sawit. Hasil penelitian Puspita \& Nugroho (2015) menyatakan bahwa TR-01, TS-02 dan TM-01 memiliki karakteristik morfologi dan anti-fungi yang sama dalam menghambat patogen.

Gambar 1 menunjukkan bahwa isolat Trichoderma spp. yang diuji memiliki interaksi yang kompatibel. Interaksi kompatibel ditandai dengan adanya garis batas yang jelas, warna spora hijau, pertumbuhan yang normal, tidak saling menghambat, tidak terjadi pertumbuhan yang berlebihan (over-growth) dan penyatuan hifa. Berdasarkan hasil penelitian Hanudin dkk. (2012), pertumbuhan yang normal antara dua atau lebih mikroba antagonis ditandai dengan adanya pertumbuhan koloni yang tidak saling menghambat. Hal ini diperkuat oleh hasil penelitian El-Refai dkk. (2013) yang menyebutkan bahwa jamur yang tidak kompatibel ditandai dengan adanya zona penghambatan, pertumbuhan yang berlebih dan penumpukan konidia disatu sisi.

Tabel 1. Kompatibilitas antar isolat Trichoderma spp. endofit.

\begin{tabular}{cccc}
\hline Isolat yang diuji & TR-01 & TS-02 & TM-01 \\
\hline TR-01 & $\mathrm{X}$ & + & + \\
TS-02 & + & $\mathrm{X}$ & + \\
TM-01 & + & + & $\mathrm{x}$ \\
\hline
\end{tabular}

Keterangan : $(-)=$ tidak kompatibel, $(+)=$ kompatibel, $(\mathrm{x})=$ tidak diuji

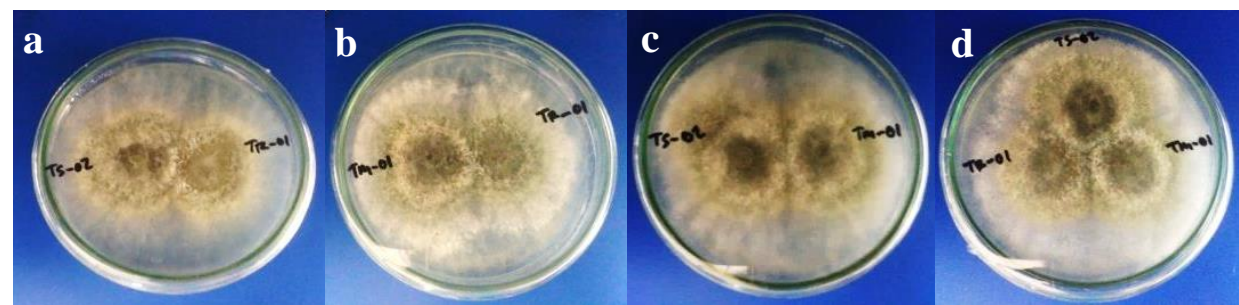

Gambar 1. Uji kompatibilitas tiga isolat Trichoderma spp. endofit. a $=$ TR-01+ TS-02, b = TR-01 + TM-01, $\mathrm{c}=\mathrm{TS}-02+\mathrm{TM}-01$ dan $\mathrm{d}=\mathrm{TR}-01+\mathrm{TS}-02+\mathrm{TM}-01$.

Daya hambat konsorsium Trichoderma spp. endofit pada medium PDA

Rata-rata hasil daya hambat Konsorsium Trichoderma spp. endofit pada medium PDA dapat dilihat pada Tabel 2. Data pada Tabel 2 menunjukkan bahwa isolat Trichoderma spp. endofit TR-01, TS-02 dan konsorsium TS-02+TM-01 serta TR-01+TS-
02+TM-01 menghasilkan daya hambat yang lebih tinggi yaitu $\geq 70 \%$ dibandingkan dengan konsorsium lainnya, namun tidak berbeda secara nyata dengan isolat secara tunggal. Konsorsium TR-01+TS-02 dan TR-01+TM-01 menunjukkan daya hambat yang lebih rendah yaitu $64,57 \%$ dan $57,22 \%$, yang berbeda nyata dengan isolat tunggal dan konsorsium lainnya. 
Tabel 2. Daya hambat isolat/konsorsium Trichoderma spp. endofit terhadap $P$. palmivora pada media PDA.

\begin{tabular}{lc}
\hline \multicolumn{1}{c}{ Isolat/konsorsium } & Daya hambat (\%) \\
\hline TR-01 & $70,00 \mathrm{a}$ \\
TS-02 & $70,60 \mathrm{a}$ \\
TM-01 & $69,82 \mathrm{ab}$ \\
TR-01+TS-02 & $64,57 \mathrm{~b}$ \\
TR-01+TM-01 & $57,22 \mathrm{c}$ \\
TS-02+TM-01 & $71,12 \mathrm{a}$ \\
TR-01+TS-02+ TM-01 & $72,97 \mathrm{a}$ \\
\hline Keterangan : Angka-angka yang diikuti oleh huruf kecil yang tidak \\
sama adalah berbeda nyata menurut hasil uji BNJ pada \\
taraf 5\% setelah ditransformasikan arsin $\sqrt{\mathrm{y}}$.
\end{tabular}

Penggunaan isolat Trichoderma spp. endofit TR-01, TS-02 dan konsorsium TS-02+TM-01 serta TR-01+TS-02+TM-01 efektif dalam menekan pertumbuhan $P$. Palmivora. Hal ini diduga pada isolat dan kombinasi ini memiliki laju pertumbuhan jamur yang cepat yaitu diatas $30 \mathrm{ml} /$ hari sehingga dapat meningkatkan kompetisi ruang dengan $P$. palmivora. Hutabalian dkk. (2015) menyatakan bahwa agens hayati yang memiliki pertumbuhan yang cepat akan memiliki kemampuan menghambat pertumbuhan patogen semakin tinggi dengan terjadi persaingan terhadap nutrisi dan ruang. Penggunaan kombinasi isolat Trichoderma spp. endofit dapat menghambat pertumbuhan $P$. palmivora karena adanya interaksi antar isolat yang saling bekerjasama dalam menghambat pertumbuhan patogen, dimana interaksi ini saling menutupi kelemahan satu isolat jamur dengan isolat lainnya dalam menghambat pertumbuhan patogen. Sesuai pendapat Suwandi (2008) yang menyatakan bahwa kombinasi beberapa jamur antagonis dapat meningkatkan penekanan penyakit tanaman.

Persentase daya hambat dari konsorsium TR-01+TM-01 menunjukkan daya hambat terendah dibandingkan dengan konsorsium lainnya yaitu sebesar $57,22 \%$. Rendahnya daya hambat konsorsium TR-01+TM-01 ini diduga adanya interaksi yang kurang optimal dalam menghambat patogen. Interaksi antara jamur antagonis yang kurang optimal dapat menyebabkan melambatnya pertumbuhan jamur. Konsorsium tersebut juga menunjukkan laju pertumbuhan koloni yang paling rendah yaitu 26,33 $\mathrm{mm} /$ hari. dibandingkan dengan konsorsium lainnya. Menurut Djafaruddin (2000), salah satu faktor penting suatu mikroorganisme antagonis dalam mengendalikan patogen adalah kecepatan pertumbuhan yang tinggi untuk berkompetisi ruang dengan patogen.

\section{Masa inkubasi $P$. palmivora pada buah kakao}

Rata-rata hasil masa inkubasi $P$. palmivora pada buah kakao dapat dilihat pada Tabel 3. Data pada Tabel 3 menunjukkan bahwa masa inkubasi $P$. palmivora pada buah kakao dengan perlakuan isolat tunggal berbeda tidak nyata dengan perlakuan konsorsium dua isolat dan tiga isolat Trichoderma spp. endofit. Hal ini menunjukkan bahwa pemberian isolat dan konsorsium Trichoderma spp. endofit memiliki kemampuan kolonisasi pada jaringan buah kakao dan mekanisme penghambatan yang sama dalam menekan pertumbuhan $P$. palmivora, sehingga menyebabkan munculnya gejala awal busuk buah kakao cenderung sama. Hasil pengamatan menunjukkan bahwa perlakuan Trichoderma spp. endofit dapat menekan gejala awal lebih dari 3 hari (>72 jam), hasil ini lebih lama dibandingkan dengan hasil penelitian Opeke \& Gorezn (1974) dalam Wahab (2007) yang menyatakan bahwa secara alami gejala awal busuk buah kakao muncul pada 30 jam setelah inokulasi.

Tabel 3. Masa inkubasi $P$. palmivora pada buah kakao setelah diberi isolat/konsorsium Trichoderma spp. endofit.

\begin{tabular}{lc}
\hline Isolat/konsorsium & Masa inkubasi (hari) \\
\hline TR-01 & $3,83 \mathrm{a}$ \\
TS-02 & $3,67 \mathrm{a}$ \\
TM-01 & $4,00 \mathrm{a}$ \\
TR-01+TS-02 & $3,67 \mathrm{a}$ \\
TR-01+TM-01 & $4,17 \mathrm{a}$ \\
TS-02+TM-01 & $4,67 \mathrm{a}$ \\
TR-01+TS-02+ & $4,83 \mathrm{a}$ \\
TM-01 &
\end{tabular}

Keterangan: Angka-angka yang diikuti oleh huruf yang sama menunjukkan tidak berbeda nyata setelah diuji lanjut BNJ pada taraf $5 \%$. setelah ditransformasi $\sqrt{y+0,5}$.

Kemampuan perlakuan konsorsium yang berbeda tidak nyata antar perlakuan diduga adanya kemampuan yang sama dari masing-masing isolat atau konsorsium dalam menghambat infeksi patogen P. palmivora. Menurut Djonovic et al. (2006) $T$. virens mampu menghasilkan enzim hidrolitik 1,6- $\beta$ glukanase dan kitin yang dapat membantu untuk melakukan penetrasi dan lisis pada hifa patogen. Dinding sel $P$. palmivora yang terhidrolisis akan mengakibatkan pertumbuhan terhambat sehingga daya infeksinya akan berkurang.

Kemampuan kolonisasi dan mekanisme penghambatan yang sama diduga disebabkan oleh jamur Trichoderma spp. endofit yang digunakan pada penelitian ini berasal dari jaringan yang berbeda dari 
tanaman kelapa sawit dan semua isolat adalah $T$. virens endofit. Saputra (2018) menyatakan bahwa jamur T. virens endofit (TR-01, TS-02 dan TM-01) dapat menghasilkan antifungi dan mampu menghambat patogen $R$. microporus. Hasil penelitian Halimah (2017) menunjukkan bahwa pemberian suspensi $T$. virens endofit dapat meningkatkan ketahanan tanaman sehingga infeksi yang disebabkan oleh Ganoderma sp. terhambat dan munculnya gejala awal lebih lama.

\section{Intensitas Serangan $P$. palmivora pada Buah Kakao}

Rata-rata hasil intensitas penyakit oleh $P$. palmivora pada buah kakao dapat dilihat pada Tabel 4. Intensitas penyakit busuk buah kakao pada perlakuan dengan konsorsium TR-01+TS-02+TM-01 menunjukkan nilai yang paling rendah yaitu 25\%, dibandingkan dengan isolat tunggal dan konsorsium dua isolat. Rendahnya intensitas penyakit busuk buah kakao pada konsorsium TR-01+TS-02+TM-01 dapat dihubungkan dengan daya hambat yang tinggi pada medium PDA (Tabel 2) yang mana konsorsium TR01+TS-02+TM-01 mampu lebih cepat menguasai ruang medium. Hal ini dapat menyebabkan konsorsium TR-01+TS-02+TM-01 lebih cepat mengolonisasi permukaan buah kakao dan menghambat infeksi $P$. palmivora. Menurut Soesanto dkk. (2013) pertumbuhan antagonis yang cepat dapat mendominasi substrat dan menghambat perkembangan patogen.

Tabel 4. Intensitas penyakit $P$. palmivora pada buah kakao setelah diberi isolat atau konsorsium Trichoderma spp. endofit.

\begin{tabular}{lc}
\hline Isolat/konsorsium & Intensitas penyakit (\%) \\
\hline TR-01 & $45,83 \mathrm{a}$ \\
TS-02 & $41,67 \mathrm{ab}$ \\
TM-01 & $37,50 \mathrm{ab}$ \\
TR-01+TS-02 & $33,33 \mathrm{ab}$ \\
TR-01+TM-01 & $29,17 \mathrm{ab}$ \\
TS-02+TM-01 & $29,17 \mathrm{ab}$ \\
TR-01+TS-02+ TM-01 & $25,00 \mathrm{~b}$ \\
\hline Keterangan : Angka-angka yang diikuti oleh huruf yang sama \\
\multicolumn{2}{c}{ menunjukkan tidak berbeda nyata setelah diuji } \\
lanjut BNJ pada taraf 5\%.
\end{tabular}

Isolat tunggal TS-02, TM-01 dan konsorsium dua isolat TR-01+TS-02, TR-01+TM-01 serta TS02+TM-01 menghasilkan intensitas penyakit busuk buah kakao yang cenderung sama pada buah kakao. Hal ini diduga adanya kecederungan yang sama dalam mengolonisasi dan menghasilkan enzim hidrolitik, sehingga penggunaan secara tunggal dan konsorsium dua isolat memiliki kemampuan yang sama dalam menghambat pertumbuhan patogen $P$. palmivora. Umrah dkk. (2009) menunjukkan bahwa penggunaan isolat Trichoderma secara tunggal dan gabungan dapat menghambat serangan $P$. palmivora pada buah kakao setelah 3 hari masa inkubasi. Selain itu sinergitas antara perlakuan dua isolat diduga masih belum efektif dalam menutupi kelemahan jamur lainnya sehingga penghambatan terhadap patogen cenderung sama dengan isolat tunggal. Menurut Suwandi (2008), sinergitas antara jamur antagonis yang efektif ditandai dengan kemampuan suatu jamur antagonis menutupi kelemahan antagonis jamur lain.

Tabel 4 juga menunjukkan bahwa intensitas serangan $P$. palmivora pada buah kakao dengan isolat TR-01 menghasilkan intensitas serangan paling tinggi yaitu $45,83 \%$. Hal ini diduga isolat yang digunakan merupakan isolat yang berasal dari akar kelapa sawit yang hidup pada habitat tanah. Jamur endofit yang berasal dari akar tanaman diaplikasikan pada lingkungan yang berbeda diduga akan memengaruhi kemampuan jamur untuk beradaptasi dan menghambat serangan patogen. Soesanto dkk. (2013) menyatakan bahwa keefektifan pengendalian hayati sangat dipengaruhi oleh kemampuan agens hayati dalam beradaptasi dengan tanaman dan lingkungannya.

Jamur antagonis endofit yang berasal dari akar akan lebih efektif untuk mengendalikan patogen tular tanah. Hasil penelitian Hutabalian dkk. (2015) menunjukkan bahwa jamur endofit dari akar pisang memiliki daya hambat lebih baik terhadap Fusarium oxysporum f.sp. cubense yang merupakan patogen tular tanah, dibandingkan dengan jamur endofit dari daun dan batang pisang. Saputra (2018) juga menyatakan bahwa jamur $T$. virens endofit yang berasal dari akar kelapa sawit lebih baik dalam menghambat $R$. microporus, dibandingkan jamur $T$. virens endofit yang berasal dari batang dan pelepah. Hal ini menunjukkan bahwa kemampuan jamur $T$. virens endofit asal akar lebih efektif dalam mengolonisasi perakaran namun kurang efektif dalam mengolonisasi jaringan buah kakao, sehingga isolat TR-01 (asal akar) belum efektif menghambat serangan $P$. palmivora pada buah kakao.

\section{SIMPULAN}

1. Isolat $T$. virens asal akar (TR-01), batang (TS-02) dan pelepah (TM-01) merupakan tiga isolat yang kompatibel dan dapat digunakan secara 
konsorsium karena mempunyai pertumbuhan yang tidak saling menghambat satu sama lain.

2. Konsorsium Trichoderma TR-01+TS-02+TM-01 merupakan perlakuan yang terbaik dalam menghambat pertumbuhan patogen $P$. palmivora dengan persentase daya hambat tertinggi (72,97\%) pada medium PDA.

3. Penggunaan Jamur Trichoderma spp. endofit baik secara tunggal maupun konsorsium memiliki kemampuan yang sama dalam menghambat munculnya gejala awal busuk buah kakao.

4. Penggunaan konsorsium Trichoderma TR01+TS-02+TM-01 mampu menekan penyakit busuk buah kakao karena $P$. palmivora hingga $75 \%$.

\section{UCAPAN TERIMA KASIH}

Penulis ucapkan terima kasih kepada pihak Fakultas Pertanian Universitas Riau dan Laboratorium Penyakit Tumbuhan yang telah memberikan fasilitas untuk pelaksanaan penelitian ini.

\section{DAFTAR PUSTAKA}

Asaad, M, BA Lologau, Nurjanani dan Warda. 2010. Kajian pengendalian penyakit busuk buah kakao terhadap Phytophthora sp. menggunakan Trichoderma sp. dan kombinasinya dengan penyarungan buah. Balai Pengkajian Teknologi Petanian Sulawesi Selatan. Makasar.

Djafaruddin. 2000. Dasar-Dasar Perlindungan Penyakit Tanaman. Bumi Aksara. Jakarta.

Djonovic, S, MJ Pozo dan CM Kenerley. 2006. Tvbgn3, a $\beta$-1,6-glucanase from the biocontrol fungus Trichoderma virens, is involved in Mycoparasitism and control of Pythium ultimum. Applied and Environmental Microbiology. 72 (12): 76617670.

Direktorat Jenderal Perkebunan. 2019. Statistika Perkebunan Indonesia Komoditas Kako. Kementerian Pertanian. Jakarta.

El-Refai, IM, SM Amer, Susan, W Assawah, dan MS Mohamed. 2013. Vegetative compatibility and strain improvement of egypitian Trichoderma isolates. Life Science Journal. 10(3): 187-197.

Fauzan, A, L Lubis, dan MI Pinem. 2013. Keparahan penyakit busuk buah kakao (Phytophthora palmivora Bult.) pada beberapa perkebunan kakao rakyat yang berada naungan di Kabupaten Langkat. Jurnal Online Agroteknologi. 1(3): 374-384.

Halimah, N. 2017. Induksi Ketahanan Bibit Kelapa Sawit (Elaeis guineensis jacq.) dengan Agen Penginduksi Berbeda Jamur Trichoderma virens Endofit Terhadap Serangan Penyakit Busuk Batang Atas. Jom Faperta. 4(2): 1-15.

Hanudin, B Marwoto, Hersanti, dan A Muharam, 2012, Kompatibilitas Bacillus substilis, Pseudomonas fluorescens dan Trichoderma harzianum untuk mengendalikan Ralstonia solanacearum pada tanaman kentang. Jurnal Hortikultura. 22(2): 173-180.

Hutabalian, M, IP Mukhtar, dan O Syahrial. 2015. Uji antagonisme beberapa jamur saprofit dan endofit dari tanaman pisang terhadap Fusarium oxyporum f.sb cubens di laboratorium. J. Online Agroteknologi. 3(2) : 687-695.

Puspita, F, dan TT Nugroho. 2015. Karakterisasi Molekular Trichoderma sp. Endofit dan Potensinya Sebagai Antifungi terhadap Ganoderma boninense Pat. dan Pemacu Pertumbuhan Bibit Kelapa Sawit. Laporan Penelitian. Universitas Riau. Pekanbaru.

Saputra, NA. 2018. Uji antagonis dan potensi senyawa antifungi tiga isolat Trichoderma virens TR01, TS02 dan TM01 endofit tanaman kelapa sawit terhadap Rigidoporus microporus secara in-vitro. Skripsi. Fakultas Pertanian Universitas Riau, Pekanbaru.

Soesanto, L, E Mugiastuti, RF Rahayuniati, dan RS Dewi. 2013. Uji kesesuaian empat isolat Trichoderma spp. dan daya hambat in vitro terhadap beberapa patogen tanaman. Jurnal HPT Tropika. 13(2): 117-123.

Supriati, L, RB. Mulyani, dan Y. Lambang. 2010. Kemampuan antagonism beberapa isolat Trichoderma sp. indigenous terhadap Sclerotium rolfsii secara in-vitro. Jurnal Agroscientic. 17(3): 119-122.

Suwandi. 2008. Evaluasi kombinasi isolat Trichoderma mikoparasit dalam mengendalikan penyakit akar putih pada bibit karet. Jurnal HPT Tropika. 8(1): 55-62.

Umrah, T Anggraeni, RR Esyanti, dan INP Aryantha. 2009. The antagonisticity and effectiveness of Trichoderma sp in controlling Phytophthora palmivora development on cocoa pod. Agroland. 16(1): 9-16. 
ISSN 0853-2885

Wahab, A. 2007. Pengenalan dan pengendalian busuk buah kakao. Buletin Teknologi dan Informasi Pertanian. Sulawesi Tenggara. 